\title{
Synergistic Protection of a General Caspase Inhibitor and MK-801 in Bilirubin-Induced Cell Death in Human NT2-N Neurons
}

\author{
ERIK HANKØ, THOR W.D. HANSEN, RUNAR ALMAAS, RAGNHILD PAULSEN, AND TERJE ROOTWELT
}

\begin{abstract}
Department of Pediatric Research [E.H., R.A., T.R.], Department of Pediatrics [T.W.R.H., T.R.], Rikshospitalet-Radiumhospitalet

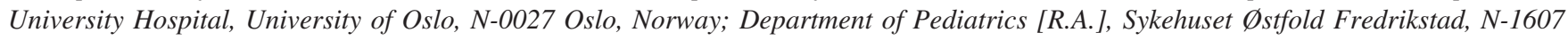
Fredrikstad, Norway; Institutes of Pharmacy [R.P.], University of Oslo, N-0316 Oslo, Norway
\end{abstract}

\begin{abstract}
Unconjugated bilirubin (UCB) induces both apoptosis and necrosis in neurons. To investigate the role of caspases and excitotoxicity in UCB-induced cell death, we exposed NT2-N neurons to $5 \mu \mathrm{M}$ UCB (a concentration known to induce apoptosis) or 2 $\mu \mathrm{M}$ staurosporine (positive apoptosis control) and investigated the effects of treatments with the specific caspase- 3 inhibitor, zDEVD.FMK (20 and $100 \mu \mathrm{M}$ ), or the general caspase inhibitor, zVAD.FMK (20 and $100 \mu \mathrm{M}$ ), and/or the $N$-methyl-D-aspartate (NMDA) receptor antagonist MK-801 $(10 \mu \mathrm{M})$ during a $24-$ or $48-\mathrm{h}$ exposure. UCB increased caspase-3 activity 2.3-fold after $6 \mathrm{~h}$. Despite this, treatment with zDEVD.FMK did not prevent cell death. zVAD.FMK (100 $\mu \mathrm{M}$ only) reduced apoptotic morphologies induced by UCB after $48 \mathrm{~h}$, however, this effect was not reflected in MTT assays. MK-801 attenuated UCB-induced cell death after $24 \mathrm{~h}$, but not significantly after $48 \mathrm{~h}$. Similar effects were seen in the MTT assay. Combined treatment with MK-801 and zVAD.FMK synergistically reduced apoptotic morphologies after 24 and $48 \mathrm{~h}$. MTT assays showed comparable effects after $24 \mathrm{~h}$ but did not show significant differences after $48 \mathrm{~h}$. We conclude that NMDA receptormediated pathways and caspase-mediated pathways are involved in UCB-induced cell death in human NT2-N neurons. Concomitant inhibition of both pathways results in synergistic protection. (Pediatr Res 59: 72-77, 2006)
\end{abstract}

$\mathrm{B}$ ilirubin-induced encephalopathy in the newborn remains an important clinical issue. However, the molecular mechanisms of neuronal death caused by UCB are incompletely understood. In vitro studies on neuronal cells from fetal and newborn rats have shown that both apoptosis- and necrosis-like neuronal deaths are implicated (1,2). Activation of proteolytic enzymes called caspases plays a key role in the execution of apoptosis. Activation of caspase-3, an important executioner caspase in a variety of cell lines, was recently reported after UCB exposure to fetal rat cortical neurons (3). Furthermore, caspase inhibition has been shown to reduce both necrosis and apoptosis in UCB-induced cell death in fetal

Received December 6, 2004; accepted June 15, 2005

Correspondence: Erik Hank $\varnothing$, M.D., Department of Pediatric Research, Rikshospitalet, N-0027 Oslo, Norway, e-mail: erikh@ulrik.uio.no

This study was supported by the intramural grants from the University of Oslo, the Blix Family Foundation, the Anders Jahre Foundation, the Neonatal Fund, Rikshospitalet, Oslo, the Norwegian Research Council, Sykehuset Østfold Fredrikstad, and Medinnova.

DOI: 10.1203/01.pdr.0000191135.63586.08 rat cortical neurons (1). Excitotoxic mechanisms have also been implicated both in vivo $(4,5)$ and in vitro $(1,6)$.

In the present study, we used a human teratocarcinomaderived cell line, NT2 cells. After treatment with retinoic acid and mitotic inhibitors, these cells develop into polarized, postmitotic, neuron-like cells, NT2-N neurons, which express NMDA and non-NMDA receptors (7). We recently showed that low and moderate concentrations of $\mathrm{UCB}(<10 \mu \mathrm{M})$ induced predominantly delayed apoptosis over $48 \mathrm{~h}(8)$. In that study, two additional markers of apoptosis, degradation of DNA into internucleosomal fragments and proteolytic cleavage of the enzyme poly(ADP ribose)polymerase (PARP), suggested a role of activated caspase- 3 in UCB induced cell death (8). In the present study, we confirmed the activation of caspase- 3 by UCB $(5 \mu \mathrm{M})$. Thereafter, we investigated the effects of treatment with caspase inhibitors and the NMDA receptor antagonist MK-801 on UCB-induced cell demise. Staurosporine (STS), a general protein kinase inhibitor that typically induces caspase-dependent cell death, was used as positive apoptosis control.

\section{MATERIALS AND METHODS}

Materials. Dulbecco's medium modified by Eagle (DMEM), fetal bovine serum, PBS, and penicillin and streptomycin solution were purchased from Invitrogen (Carlsbad, CA). Polylysine and Matrigel were from Becton Dickinson (Bedford, MA). UCB, BSA, MTT (3-4[4,5-dimethylthiazol-2-yl]-2,5diphenyltetrazoliumbromide), retinoic acid, uridine, 5-fluoro-2'-deoxyuridine, and cytosine arabinofuranoside were from Sigma Chemical Co. (St. Louis, MO). BSA was dissolved in deionized water. MTT $(0.5 \mathrm{mg} / \mathrm{mL})$ was dissolved in PBS with $5.5 \mathrm{mM}$ glucose. The fluorescent dyes Hoechst 33342 and ethidium homodimer (both Molecular Probes Inc., Eugene, OR) were diluted in DMSO. Staurosporine (Roche Molecular Biochemicals, Mannheim, Germany) was dissolved in DMSO to a $2 \mathrm{mM}$ stock. The caspase inhibitors zDEVD.FMK and zVAD.FMK (R \& D Systems Europe Ltd., Abingdon, UK) were stored as $20 \mathrm{mM}$ stocks in DMSO and used within $2 \mathrm{mo}$. MK-801 (Sigma Chemical Co.) was dissolved in water as a $10 \mathrm{mM}$ stock solution. All solutions were stored at $-20^{\circ} \mathrm{C}$. NTera2/c1.D1 (NT2) cells were cultured as previously described $(9,10)$.

Abbreviations: EH, ethidium homodimer; LDH, lactate dehydrogenase; MTT, 3-4[4,5-dimethylthiazol-2-yl]-2,5-diphenyltetrazoliumbromide; NMDA, $N$-methyl-D-aspartate; UCB, unconjugated bilirubin; zDEVD.FMK, z-aspglu-val-asp-fluoromethyl ketone (caspase-3 inhibitor); zVAD.FMK, z-valala-asp-fluoromethyl ketone (general caspase inhibitor) 
Exposure to bilirubin and inhibitors. Before each experiment, UCB was dissolved in $0.1 \mathrm{M} \mathrm{NaOH}$ and deionized water to a concentration of $5 \mathrm{mM}$ $\mathrm{UCB}$, and immediately added to a BSA solution to obtain a UCB/BSA molar ratio of 1.5. All handling of bilirubin was performed in dim light. Serum-free DMEM with penicillin $(100 \mathrm{IU} / \mathrm{mL})$ and streptomycin $(100 \mu \mathrm{g} / \mathrm{mL})$ was added to each well after washing the cells twice in PBS 10 min before the experiments. Cells exposed to $\mathrm{NaOH}$ and BSA only served as controls in all experiments. One of the two caspase-inhibitors, zDEVD.FMK or zVAD.FMK (both 20 and $100 \mu \mathrm{M}), \mathrm{MK}-801(10 \mu \mathrm{M})$, or the combination of a caspase inhibitor and MK-801 was added 2 min before incubation with UCB or $2 \mu \mathrm{M}$ STS. Wells in a 12-well plate were randomly selected for different treatments. To minimize UCB precipitation, the experiments were performed with slightly supra-physiologic $\mathrm{pH}$. We have previously shown in our model that $\mathrm{pH}$ drops from 7.59 at the beginning of incubation to 7.52 after $24 \mathrm{~h}(8)$. The cultures were incubated for $3-48 \mathrm{~h}$ at $37^{\circ} \mathrm{C}$ in a mixture of $95 \%$ room air and $5 \% \mathrm{CO}_{2}$.

Caspase-3 activity. After treatment with UCB or STS, the medium was aspirated, and the cultures were washed twice with PBS and then lysed with $500 \mu \mathrm{L}$ RIPA buffer $(50 \mathrm{mM}$ Tris- $\mathrm{HCl}, \mathrm{pH} 7.4,1 \%$ Igepal, $0.25 \%$ sodium deoxycholate, $150 \mathrm{mM} \mathrm{NaCl}$, and $1 \mathrm{mM}$ EGTA) for $5 \mathrm{~min}$ at room temperature. Two hundred microliters of cell lysate was transferred to a 96-well plate and incubated with $20 \mu \mathrm{M}$ caspase-3 fluorometric substrate, AcDEVD.CMC (Upstate Biotech, Lake Placid, NY). Caspase-3 inhibitor (5 $\mu \mathrm{M}$ zDEVD. FMK) was added to some wells as negative controls. Samples were incubated at $37^{\circ} \mathrm{C}$ and fluorescence was measured after $60 \mathrm{~min}$ at excitation $360 \mathrm{~nm}$ and emission $460 \mathrm{~nm}$, using a fluorometer (Perkin-Elmer HTS 7000 Plus, Bio Assay Reader, Norwalk, CT). Fluorescence activity was normalized to protein content (BCA Protein Assay Kit, Pierce Biotechnology, Inc., Rockford, IL).

MTT reduction. The MTT assay relies on the cleavage of the tetrazolium salt by viable cells, and it is a commonly used method for measuring cellular viability (11). After treatment with UCB or STS the cultures were washed twice with PBS and $0.5 \mathrm{~mL}$ MTT solution was added. After 60 min incubation $\left(37^{\circ} \mathrm{C}, 5 \% \mathrm{CO}_{2}\right)$ the MTT solution was aspirated and replaced with $0.5 \mathrm{~mL}$ of DMSO to dissolve the formazan crystals produced by MTT reduction. Absorbance was read at $570 \mathrm{~nm}$ and background at $660 \mathrm{~nm}$ was subtracted in a Titertek multiscan Plus MK1-ELISA reader (Labsystems and Life Sciences International Ltd., Haver Hill, UK). Results are given in percentage of MTT reduction in controls.

Assessment of nuclear morphology with fluorescent dyes. The evaluation of nuclear morphology is a cornerstone in the assessment of cell death pathways. After incubation with UCB or STS, the neurons were washed twice with PBS and incubated with Hoechst $(5 \mathrm{mg} / \mathrm{mL})$ and $\mathrm{EH}(2 \mathrm{mM})$ for $15 \mathrm{~min}$. Whereas Hoechst 33342 stains the nuclei of all living and dead cells, ethidium homodimer (EH) exclusively stains the nuclei of cells with disintegrated cell membranes, as seen in necrosis. A UV excitation filter $(340-380 \mathrm{~nm})$ and a green excitation filter $(515-560 \mathrm{~nm})$ were used for each motif, as previously described (12). The cells were visualized by an inverted fluorescent microscope (Model DM IRB, Leica Microscopy, Herburg, Switzerland) and photographed with a digital camera (Kodak, DC 120 ZOOM Digital Camera, Eastman Kodak Company, Rochester, NY) for later analysis. Neurons with intact membranes (exclusively stained with Hoechst) displaying uncondensed nuclear chromatine were considered undamaged. Apoptotic cells were identified either as shrunken nuclei with condensed chromatine and intact membranes, labeled as condensed, or as nuclei with distinct fragmentation (at least two distinct lobuli) labeled as fragmented. Condensed nuclei with uptake of $\mathrm{EH}$, compatible with necrotic cell death, were labelled as condensed with disrupted membrane. We have previously demonstrated the principal patterns of changes in nuclear morphologies induced by STS and UCB in this cell line (8). In general, cells of all categories remained adherent to the dish, and detached nuclei accounted for $<2 \%$ of the total cell count. All cells were counted by the same investigator. A subset of neurons was counted by an independent investigator to an interobserver agreement of $>95 \%$. Prevalence of the different morphologic categories is given in percentage of the total number of cells counted for each experimental condition (at least 700 cells).

DNA fragmentation analysis. DNA electrophoresis was performed to determine the effects of treatments with caspase inhibitors and/or MK-801 on DNA degradation. To evaluate the impact of caspase inhibition on DNA fragmentation, analysis was performed with a kit, Wizard SV genomic DNA purification system (Promega Corporation, Madison, WI). After $24 \mathrm{~h}$ of incubation, the cells were washed twice with PBS, lysed, and genomic DNA was isolated. The extracted DNA (from two wells) was fractionated in a $1.5 \%$ agarose gel electrophoresis with ethidium bromide staining. The gel was then examined under UV light for visualization and photographed.

Statistics. Cells from at least six wells from at least three separate experiments were examined for all experimental conditions. Data are given as mean \pm SD. Statistical significance was calculated using a $t$ test. Welch's correction was applied if variances between two groups differed significantly. Bonferroni corrections were not applied. We tested for the effects of i) treatment with both concentrations of both caspase inhibitors and MK-801 as single treatments versus no treatment, ii) high-dose versus low-dose caspase inhibitor, and iii) additive protection of a caspase inhibitor combined with MK-801 compared with treatment with MK-801 alone. A two-tailed $p<0.05$ was considered statistically significant.

\section{RESULTS}

UCB induces moderate caspase-3 activation. Control cells, treated as previously described, showed a small increase in caspase- 3 activity at $3 \mathrm{~h}$, returning toward basal conditions at 24 h (Fig. 1). "Basal conditions" was defined as the level of caspase activation in cells exposed neither to medium change nor serum deprivation (cells left undisturbed in serum containing medium). Neurons exposed to $5 \mu \mathrm{M}$ UCB displayed an increase in activated caspase- 3 to $230 \%$ of controls after $6 \mathrm{~h}(p<0.05)$, but returned toward basal levels at $24 \mathrm{~h}$. STS induced a large increase in caspase- 3 activity, reaching $780 \%$ of controls at $6 \mathrm{~h}$ and returning toward basal levels at $24 \mathrm{~h}$ (Fig. 1). Concomitant treatment with MK-801 did not influence caspase-3 activity (at any time point) in neurons treated with STS or $5 \mu \mathrm{M}$ UCB $(38 \pm 18$ units $/ \mu \mathrm{g}$ protein after UCB treatment only versus $35 \pm 13$ units $/ \mu \mathrm{g}$ protein after $\mathrm{UCB}$ and MK-801 at $6 \mathrm{~h}$ ).

General caspase inhibitor, zVAD.FMK, reduces apoptotic nuclear fragmentation. Treatment with caspase inhibitors or MK-801 alone did not cause toxicity compared with controls when evaluated with MTT reduction assays and nuclear morphology ( $n=5-6$, data not shown). Exposure to UCB re-

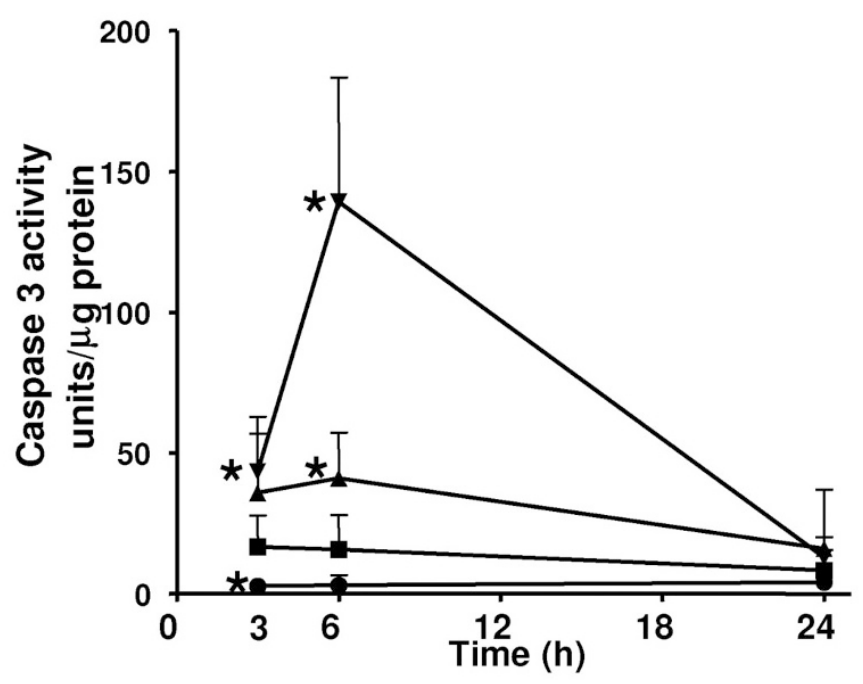

Figure 1. Caspase-3 activity measured as cleavage of the caspase-3 fluorometric substrate Ac-DEVD.cmk. Control cells were exposed to normal procedure with replacement of serum-containing medium with serum-deprived medium without UCB. "Basal conditions" were defined as caspase-3 activation in cells exposed neither to medium change nor serum deprivation. Fluorescence signal was measured after $60 \mathrm{~min}$ incubation at $37^{\circ} \mathrm{C}$. Values are given as fluorescence signal per microgram protein. $2 \mu \mathrm{M}$ Staurosporine ( $\mathbf{\nabla})$; $5 \mu \mathrm{M}$ UCB $(\mathbf{\Delta})$; control $(\mathbf{\square})$; basal conditions $(\bullet)$. *Significant difference from controls $(p<0.05)$. Data are given as mean \pm SD $(n=6-9)$. 

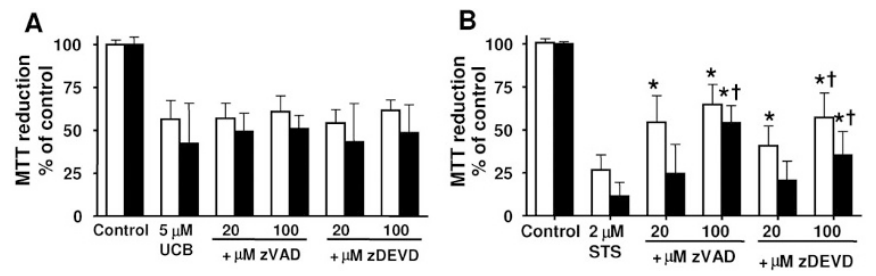

Figure 2. Cell viability as measured with MTT reduction assays in neurons exposed to $5 \mu \mathrm{M}$ UCB $(A)$ and neurons exposed to $2 \mu \mathrm{M}$ STS $(B)$. Neurons were treated with the specific caspase-3 inhibitor zDEVD.FMK or the pancaspase inhibitor zVAD.FMK (both 20 or $100 \mu \mathrm{M}$ ) for $24 \mathrm{~h}(\square)$ or $48 \mathrm{~h}(\mathbf{\square})$. *Significant difference from neurons exposed to $5 \mu \mathrm{M} \mathrm{UCB}$ alone $(p<0.05)$. ${ }^{\dagger}$ Concentration-dependent differences of the respective caspase inhibitor $(p<$ $0.05)$. Data are given as mean \pm SD $(n=6-9)$.

sulted in reduction in cell viability as measured with MTT assays (Fig. 2 A). Neither treatment with the specific caspase-3 inhibitor zDEVD.FMK nor the general caspase inhibitor zVAD.FMK enhanced viability as assayed with MTT. In contrast, both caspase inhibitors dose dependently enhanced MTT reduction for up to $48 \mathrm{~h}$ in cells exposed to STS (Fig. 2B).

Cell death in neurons exposed to $5 \mu \mathrm{M}$ UCB occurred primarily as apoptotic nuclear fragmentation or condensation compatible with apoptosis, and to a lesser extent as condensed nuclei with disrupted membrane compatible with necrosis (Fig. 3, A-D). The two different caspase inhibitors had little impact on neuronal survival (undamaged nuclei), except for a small increase in the proportion of undamaged nuclei at $48 \mathrm{~h}$ in cells treated with $100 \mu \mathrm{M}$ zVAD.FMK, suggesting an impact of general caspase inhibition on delayed apoptosis (Fig. 3A). Despite the limited effect on undamaged nuclei, treatment with zVAD.FMK and high-dose zDEVD.FMK efficiently reduced nuclear fragmentation for up to $48 \mathrm{~h}$ (Fig. $3 B$ ). Both caspase inhibitors given at the higher concentration increased the proportion of late nuclear condensation (Fig. $3 C$ ), suggesting a shift in morphology from fragmentation to condensation.
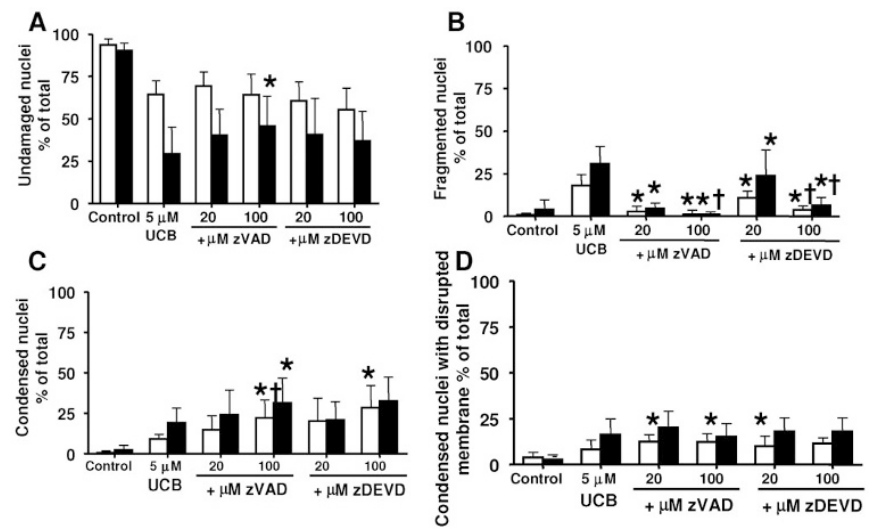

Figure 3. Nuclear morphology in percentage of total cells counted after exposure to $5 \mu \mathrm{M}$ UCB and treatment with the specific caspase- 3 inhibitor zDEVD.FMK or the pancaspase inhibitor zVAD.FMK $(20$ or $100 \mu \mathrm{M})$ for $24 \mathrm{~h}(\square)$ or $48 \mathrm{~h}(\square)$. The relative proportion of undamaged nuclei $(A)$, fragmented nuclei $(B)$, condensed nuclei $(C)$, and condensed nuclei with disrupted membrane $(D)$ for each treatment is given. $*$ Significant difference from neurons exposed to $5 \mu \mathrm{M} \mathrm{UCB}$ alone $(p<0.05)$. ${ }^{\dagger}$ Concentrationdependent differences of the respective caspase inhibitor $(p<0.05)$. Data are given as mean $\pm \mathrm{SD}(n=6-9)$.

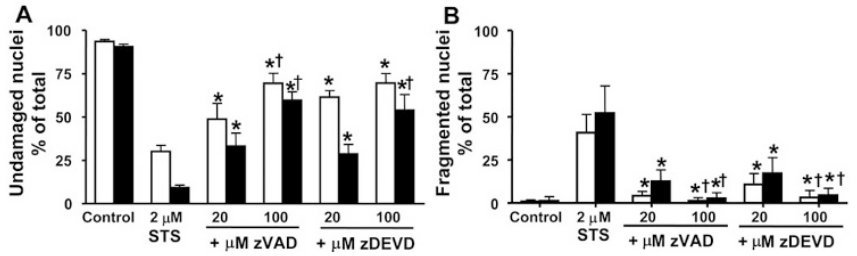

Figure 4. Nuclear morphology in percentage of total cells counted after exposure to $2 \mu \mathrm{M}$ STS and treatment with the specific caspase-3 inhibitor zDEVD.FMK or the pancaspase inhibitor zVAD.FMK $(20$ or $100 \mu \mathrm{M})$ for $24 \mathrm{~h}(\square)$ or $48 \mathrm{~h}(\square)$. The relative proportion of undamaged nuclei $(A)$ and fragmented nuclei $(B)$ are given. *Significant difference from neurons exposed to $5 \mu \mathrm{M}$ UCB alone $(p<0.05)$. Concentration-dependent differences of the respective caspase inhibitor $(p<0.05)$. Data are given as mean $\pm \mathrm{SD}(n=$ $6-9)$.

In contrast to neurons treated with UCB, both caspase inhibitors dose dependently and highly significantly increased the proportion of undamaged nuclei for up to $48 \mathrm{~h}$ in STSinduced cell injury (Fig. 4 A). Apparently, this effect was primarily due to efficient reduction in the progress to nuclear fragmentation (Fig. 4B), as caspase inhibition only caused minor changes in the proportion of condensed nuclei (data not shown).

Combined treatment with MK-801 and zVAD.FMK synergistically protects against cell death. MK-801 significantly reduced UCB-induced neuronal death as measured with MTT assays after $24 \mathrm{~h}$, but not after $48 \mathrm{~h}$ (Fig. $5 \mathrm{~A}$ ). The combination of MK-801 and zVAD.FMK $(100 \mu \mathrm{M})$, but not zDEVD.FMK $(20 \mu \mathrm{M})$ induced synergistic protection at $24 \mathrm{~h}$, as measured with MTT assays (Fig. 5A). Evaluation with nuclear morphology confirmed synergistic protection in that combined treatment resulted in near-complete protection after $24 \mathrm{~h}$ (Fig. 6A) and was still significant after $48 \mathrm{~h}$. STS-treated neurons revealed similar results evaluated with MTT assays (Fig. 5B) and nuclear morphology (data not shown).

In cells exposed to UCB, treatment with MK-801 alone did not influence the number of cells displaying fragmented nuclei (Fig. 6B) but almost abolished nuclear condensation (Fig. 6C). In combination with zVAD.FMK, the proportion of fragmented nuclei was greatly reduced, suggesting impact on separate steps in the cell death pathway by zVAD.FMK and MK-801 (Fig. 6B). STS-exposed neurons showed similar patterns for nuclear morphologic changes as in seen in UCBinduced injury in that MK-801 given alone prevented nuclear condensation for up to $48 \mathrm{~h}$ (data not shown).

General caspase inhibition, but not caspase-3 inhibition, prevents internucleosomal DNA degradation after UCB exposure. DNA fragmentation in apoptosis is a two-step process in which DNA is first cleaved into large fragments of 50-300 $\mathrm{kb}$ (13). The second step often involves activated caspase-3. DNA is cleaved into $50-\mathrm{kb}$ fragments and subsequently into internucleosomal fragments $<2 \mathrm{~kb}$, appearing as the so-called DNA ladder in the DNA electrophoresis $(13,14)$. Incubation with both STS and UCB induced internucleosomal DNA fragmentation suggestive of a role of activated caspase-3 (Fig. 7). Treatment with zDEVD.FMK $(20 \mu \mathrm{M})$ did not reduce UCB-induced DNA fragmentation, whereas STS-induced 
A
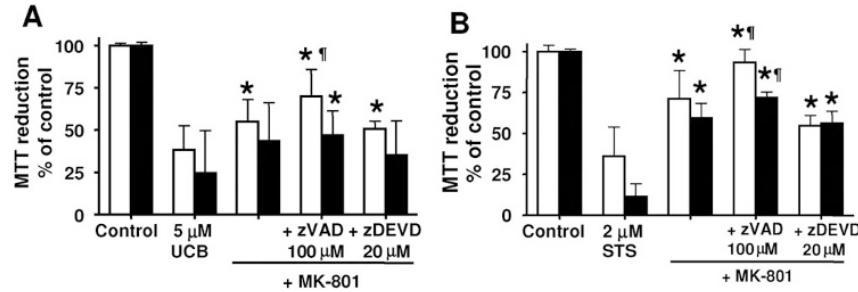

Figure 5. Effects of the NMDA receptor antagonist MK-801 $(10 \mu \mathrm{M})$ alone or in combination with zVAD.FMK $(100 \mu \mathrm{M})$ or zDEVD.FMK $(20 \mu \mathrm{M})$ after exposure to $5 \mu \mathrm{M} \mathrm{UCB}(A)$ or $2 \mu \mathrm{M}$ STS $(B)$. MTT reduction was measured after $24 \mathrm{~h}(\square)$ or $48 \mathrm{~h}(\mathbb{\square})$. *Significant difference from neurons exposed to $5 \mu \mathrm{M} \mathrm{UCB}(p<0.05)$. "Additive protection of a caspase inhibitor combined with MK-801 when compared with treatment with MK-801 alone $(p<0.05)$. Values given are the mean \pm SD $(n=6-10)$.
A
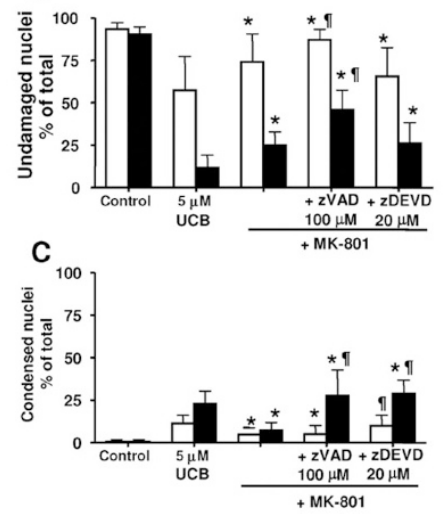

B
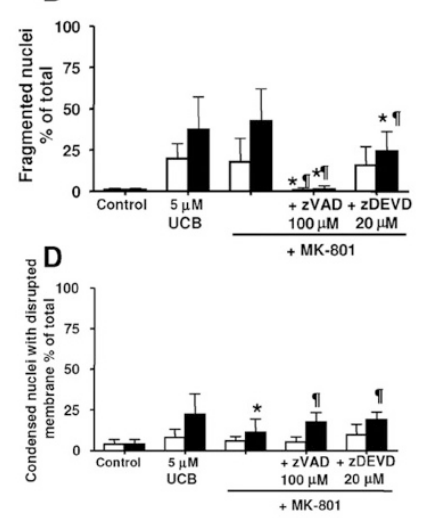

Figure 6. Nuclear morphology in percentage of total cells counted after exposure to $5 \mu \mathrm{M} \mathrm{UCB}$ and treatment with the NMDA receptor antagonist MK-801 $(10 \mu \mathrm{M})$ alone or in combination with zDEVD.FMK $(20 \mu \mathrm{M})$ or zVAD.FMK $(100 \mu \mathrm{M})$. The relative proportions of undamaged nuclei $(A)$, fragmented nuclei $(B)$, condensed nuclei $(C)$, and condensed nuclei with disrupted membrane $(D)$ after $24 \mathrm{~h}(\square)$ or $48 \mathrm{~h}(\boldsymbol{\square})$ are given. ${ }^{*}$ Significant difference from neurons exposed to $5 \mu \mathrm{M} \mathrm{UCB}$ alone $(p<0.05)$. " Additive protection of a caspase inhibitor combined with MK-801 when compared with treatment with MK-801 alone $(p<0.05)$. Data are given as mean $\pm \mathrm{SD}(n=$ $7-11)$.

DNA fragmentation was nearly abolished. In contrast, treatment with zVAD.FMK $(100 \mu \mathrm{M})$ completely abolished DNA laddering in neurons exposed to UCB or STS, both given alone and as co-treatment with MK-801 $(10 \mu \mathrm{M})$. MK-801 alone had no impact on DNA fragmentation.

\section{DISCUSSION}

The principal finding of the present study was that UCBinduced apoptosis was not prevented by caspase- 3 inhibition, and only to a limited degree by a general caspase inhibitor. Marked protective effects of general caspase inhibition was only observed when it was combined with MK-801 to prevent NMDA receptor-mediated effects. Nuclear morphology and DNA electrophoresis suggest that this synergism was due to inhibition of separate steps in the cell death pathways by caspase inhibition and MK-801.

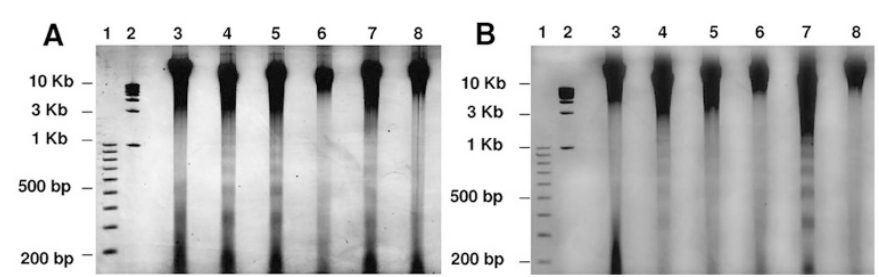

Figure 7. DNA-electrophoresis after incubation with $5 \mu \mathrm{M} \mathrm{UCB}(A)$ or 2 $\mu \mathrm{M}$ STS $(B)$ for $24 \mathrm{~h}$ and treatments as indicated in the figure. Molecular size standards are given in lanes 1 and 2. Lane 3 shows control cells subjected to serum deprivation and treatment with $\mathrm{NaOH}$ and $\mathrm{BSA}$ alone, Lane 4: UCB or STS alone, Lane 5: +zDEVD.fmk, Lane 6: +zVAD.fmk, Lane 7: +MK-801, and Lane 8: +MK-801+zVAD.fmk.

The execution of caspase-mediated apoptosis is thought to be the result of a cascade of events converging in the activation of the executioner caspases $-3,-6$, or -7 , where caspase-3 has been identified as a major downstream execution caspase (15). In the present study, treatment with the apoptosisinducer STS evoked a large activation of caspase-3. Dosedependent neuronal protection was achieved with both caspase-3 inhibition and general caspase inhibition as measured with MTT assays and nuclear morphology. However, in spite of significant caspase- 3 activation by UCB, treatment with zDEVD.FMK had no impact on neuronal survival. Treatment with zVAD.FMK slightly increased the number of undamaged nuclei at $48 \mathrm{~h}$ but had no impact on neuronal metabolism as measured with MTT assay. As suggested by several authors, a possible explanation for this discrepancy between morphology and MTT assay is that, although caspase inhibitors block the execution of apoptosis leading to morphologic changes, they do not prevent more "toxic" events such as diminished MTT reduction $(16,17)$.

Both caspase inhibitors inhibited nuclear fragmentation and DNA degradation $<2 \mathrm{~kb}$ (DNA laddering) in STS-treated neurons. In UCB-treated neurons, zDEVD.FMK did not prevent DNA laddering. In contrast, zVAD.FMK completely inhibited DNA laddering and was more potent in inhibiting nuclear fragmentation than zDEVD.FMK. zVAD.FMK protected against UCB-induced cell death by reducing the proportion of cells displaying fragmented nuclei. Although some cells instead showed nuclear condensation, an increased proportion of cells remained undamaged at $48 \mathrm{~h}$. Our data suggest the participation of executioner caspases like caspase- 6 or -7 in UCB-mediated cell death in this cell line. Activated caspase-3 may contribute to nuclear fragmentation but seems to have little impact on the cell death.

It is well documented that glutamate-mediated excitotoxicity over the ionotropic NMDA receptor may cause both apoptosis and necrosis $(18,19)$. NMDA injections into the brain caused greater damage in hyperbilirubinemic Gunn rats than in nonjaundiced controls, and concurrent treatment with MK-801 reduced this injury (5). Conflicting data exist as to whether this increased neuronal damage is due to enhanced sensitivity of the NMDA receptor to glutamate in the presence of bilirubin $(4,20)$. In the present study, MK-801 protected against UCB-induced cell death by reducing the proportion of cells displaying condensed nuclei, but had no impact on the 
number of cells showing nuclear fragmentation. Also, MK801 did not influence UCB- or STS-induced caspase-3 activation or DNA degradation. Combined treatment with MK801 and zVAD.FMK synergistically reduced apoptosis after UCB treatment. The present study strongly suggested that this synergism was due to the inhibition of different steps in the cell death pathways as previously reported in studies of neuronal hypoxia both in vivo and in vitro $(21,22)$.

MK-801 has both pro-apoptotic and neuroprotective actions (23). Several studies in cortical cell cultures from rodents report that the administration of MK-801 alone induces apoptosis by activating caspase-3 $(24,25)$. On the other hand, blockade of cellular injury induced by glutamate or NMDA by MK-801 may reduce apoptosis $(18,19)$, compatible with the results of the present study. As previously reported, treatment with MK-801 protected against STS-induced injury in this cell line (12). This protection may be due to blockade of glutamate released from damaged cells exposed to STS. Similarly, we cannot exclude the possibility that the protection by MK- 801 in UCB-induced injury is related to a reduction in additional stress mediated by glutamate in the culture medium rather than UCB-specific modulation of the NMDA receptor (4). A confirmation of specific UCB-induced excitotoxicity over the NMDA receptor still requires further investigation. The conduct of our experiments at slightly alkaline $\mathrm{pH}$ (7.52-7.59) may have contributed to exacerbation of excitotoxic injury, as alkalosis increases the susceptibility of the NMDA receptor to glutamate $(26,27)$.

In cultured cells from embryonic rat forebrain, treatments with a specific caspase-1 inhibitor or a specific caspase-3 inhibitor as well as MK-801 $(10 \mu \mathrm{M})$ completely protected against UCB-induced apoptosis and necrosis after a $96 \mathrm{~h}$ exposure to $0.5 \mu \mathrm{M}$ UCB (without albumin vehicle) (1). The authors conclude that UCB-induced caspase activation is mediated by the NMDA glutamate receptor subtype, while our results indicate that excitotoxicity is independent of caspase activation. A similar study by the same group showed that MK-801 protected against injury induced by the combination of $0.5 \mu \mathrm{M} \mathrm{UCB}$ and hypoxia (6). Both duration of exposure and the use of lower UCB concentrations may account for the differences to the present study. Our data do not exclude the possibility that cell death after long-term exposure to very low UCB concentrations may be reduced by caspase inhibitors. In addition, species differences may have contributed to the different impact of treatments in the present and the two mentioned studies.

A limitation of the present study is that caspase inhibitors with the recognition sequence zDEVD.FMK are potent inhibitors of caspase- 3 and -7 , but they also inhibit the caspases-6, -8 , and -10 at high concentrations (28). The lower zDEVD.FMK concentration $(20 \mu \mathrm{M})$ only marginally differed from $100 \mu \mathrm{M}$ zDEVD.FMK in reducing STS-induced cell death at $24 \mathrm{~h}$ and was therefore chosen in combination with MK-801 to limit the problem of specificity.

In conclusion, our data suggest that both NMDA-mediated pathways and caspase-mediated pathways, where activated caspase- 3 seems to play a minor role in the determination of cell death, are involved in UCB-mediated cell demise. The strategy of combining agents to inhibit both pathways was more successful than individual treatments in reducing cell death.

Acknowledgments. The authors thank Julie K. Lindstad, Carola Rosseland, and Luisa Luna for their excellent technical assistance.

\section{REFERENCES}

1. Grojean S, Koziel V, Vert P, Daval JL 2000 Bilirubin induces apoptosis via activation of NMDA receptors in developing rat brain neurons. Exp Neurol 166:334-341

2. Rodrigues CM, Sola S, Brites D 2002 Bilirubin induces apoptosis via the mitochondrial pathway in developing rat brain neurons. Hepatology 35:1186-1195

3. Rodrigues CMP, Sola S, Brito MA, Moura JG, Brites D 2001 Bilirubin activates caspase-3-dependent apoptotic signaling cascade. J Hepatol 34:78

4. Hoffman DJ, Zanelli SA, Kubin J, Mishra OP, Delivoria-Papadopoulos M 1996 The in vivo effect of bilirubin on the $N$-methyl-D-aspartate receptor/ion channel complex in the brains of newborn piglets. Pediatr Res 40:804-808

5. McDonald JW, Shapiro SM, Silverstein FS, Johnston MV 1998 Role of glutamate receptor-mediated excitotoxicity in bilirubin-induced brain injury in the Gunn rat model. Exp Neurol 150:21-29

6. Grojean S, Lievre V, Koziel V, Vert P, Daval JL 2001 Bilirubin exerts additional toxic effects in hypoxic cultured neurons from the developing rat brain by the recruitment of glutamate neurotoxicity. Pediatr Res 49:507-513

7. Younkin DP, Tang CM, Hardy M, Reddy UR, Shi QY, Pleasure SJ, Lee VM, Pleasure D 1993 Inducible expression of neuronal glutamate receptor channels in the NT2 human cell-line. Proc Natl Acad Sci U S A 90:2174-2178

8. Hanko E, Hansen TW, Almaas R, Lindstad J, Rootwelt T 2005 Bilirubin induces apoptosis and necrosis in human NT2-N neurons. Pediatr Res 57:179-184

9. Almaas R, Saugstad OD, Pleasure D, Rootwelt T 2000 Effect of barbiturates on hydroxyl radicals, lipid peroxidation, and hypoxic cell death in human NT2-N neurons. Anesthesiology 92:764-774

10. Rootwelt T, Dunn M, Yudkoff M, Itoh T, Almaas R, Pleasure D 1998 Hypoxic cell death in human NT2-N neurons: involvement of NMDA and non-NMDA glutamate receptors. J Neurochem 71:1544-1553

11. Liu Y, Peterson DA, Kimura H, Schubert D 1997 Mechanism of cellular 3-(4,5dimethylthiazol-2-yl)-2,5-diphenyltetrazolium bromide (MTT) reduction. J Neurochem 69:581-593

12. Almaas R, Pytte M, Lindstad JK, Wright M, Saugstad OD, Pleasure D, Rootwelt T 2003 Acidosis has opposite effects on neuronal survival during hypoxia and reoxygenation. J Neurochem 84:1018-1027

13. Walker PR, Leblanc J, Smith B, Pandey S, Sikorska M 1999 Detection of DNA fragmentation and endonucleases in apoptosis. Methods 17:329-338

14. Susin SA, Daugas E, Ravagnan L, Samejima K, Zamzami N, Loeffler M, Costantini P, Ferri KF, Irinopoulou T, Prevost MC, Brothers G, Mak TW, Penninger J, Earnshaw WC, Kroemer G 2000 Two distinct pathways leading to nuclear apoptosis. J Exp Med 192:571-580

15. Meguro T, Chen B, Lancon J, Zhang JH 2001 Oxyhemoglobin induces caspasemediated cell death in cerebral endothelial cells. J Neurochem 77:1128-1135

16. Chang LK, Putcha GV, Deshmukh M, Johnson EM Jr 2002 Mitochondrial involvement in the point of no return in neuronal apoptosis. Biochimie 84:223-231

17. Lobner D 2000 Comparison of the LDH and MTT assays for quantifying cell death: validity for neuronal apoptosis? J Neurosci Methods 96:147-152

18. Ankarcrona M, Dypbukt JM, Bonfoco E, Zhivotovsky B, Orrenius S, Lipton SA, Nicotera P 1995 Glutamate-induced neuronal death: a succession of necrosis or apoptosis depending on mitochondrial function. Neuron 15:961-973

19. Nicotera P, Leist M, Manzo L 1999 Neuronal cell death: a demise with different shapes. Trends Pharmacol Sci 20:46-51

20. Warr O, Mort D, Attwell D 2000 Bilirubin does not modulate ionotropic glutamate receptors or glutamate transporters. Brain Res 879:13-16

21. Ma J, Endres M, Moskowitz MA 1998 Synergistic effects of caspase inhibitors and MK-801 in brain injury after transient focal cerebral ischaemia in mice. Br J Pharmacol 124:756-762

22. Allen JW, Knoblach SM, Faden AI 1999 Combined mechanical trauma and metabolic impairment in vitro induces NMDA receptor-dependent neuronal cell death and caspase-3-dependent apoptosis. FASEB J 13:1875-1882

23. Husson I, Mesples B, Medja F, Leroux P, Kosofsky B, Gressens P 2004 Methylphenidate and MK-801, an N-methyl-D-aspartate receptor antagonist: shared biological properties. Neuroscience 125:163-170

24. Takadera T, Matsuda I, Ohyashiki T 1999 Apoptotic cell death and caspase-3 activation induced by $N$-methyl-D-aspartate receptor antagonists and their prevention by insulin-like growth factor I. J Neurochem 73:548-556 
25. Yoon WJ, Won SJ, Ryu BR, Gwag BJ 2003 Blockade of ionotropic glutamate receptors produces neuronal apoptosis through the Bax-cytochrome Ccaspase pathway: the causative role of $\mathrm{Ca} 2+$ deficiency. J Neurochem 85:525-533

26. Giffard RG, Weiss JH, Choi DW 1992 Extracellular alkalinity exacerbates injury of cultured cortical neurons. Stroke 23:1817-1821

27. Hurn PD, Koehler RC, Traystman RJ 1997 Alkalemia reduces recovery from global cerebral ischemia by NMDA receptor-mediated mechanism. Am J Physiol 272:H2557-H2562

28. Slagsvold HH, Rosseland CM, Jacobs C, Khuong E, Kristoffersen N, Gaarder M, Fallgren AB, Huitfeldt HS, Paulsen RE 2003 High molecular weight DNA fragments are processed by caspase sensitive or caspase independent pathways in cultures of cerebellar granule neurons. Brain Res 984:111-121 